Décadrages Décadrages

cinéma, à travers champs Cinéma, à travers champs

29-30 | 2015

René Vautier

\title{
René Vautier et le cinéma ouvrier : l'UPCB, une structure de production au service des « colonisés de l'intérieur»"
}

François Bovier et Cédric Fluckiger

\section{(2) OpenEdition \\ Journals}

Édition électronique

URL : https://journals.openedition.org/decadrages/802

DOI : $10.4000 /$ decadrages. 802

ISSN : 2297-5977

Éditeur

Association Décadrages

Édition imprimée

Date de publication : 1 avril 2015

Pagination : 116-141

ISBN : 9782970096306

ISSN : 2235-7823

Référence électronique

François Bovier et Cédric Fluckiger, «René Vautier et le cinéma ouvrier : I'UPCB, une structure de production au service des « colonisés de l'intérieur » », Décadrages [En ligne], 29-30 | 2015, mis en ligne le 01 mars 2017, consulté le 26 mars 2023. URL : http://journals.openedition.org/decadrages/802 ; DOI : https://doi.org/10.4000/decadrages.802

\section{(c) (i) (2) (2)}

Creative Commons - Attribution - Pas d'Utilisation Commerciale - Partage dans les Mêmes Conditions 4.0 International - CC BY-NC-SA 4.0

https://creativecommons.org/licenses/by-nc-sa/4.0/ 
1 Voir Hans Schoots, Living Dangerously. A Biography of Joris Ivens, Amsterdam, Amsterdam University Press, 2000; Kees Bakker (éd.), Joris Ivens and the Documentary Context, Amsterdam, Amsterdam University Press, 1999. Se reporter également aux témoignages d'Ivens sur sa pratique: Joris Ivens, The Camera and I, Berlin, Seven Sea Books, 1969.

2 Surce point, voir René Vautier, Caméra citoyenne: Mémoires, Rennes, Apogée, 1998, pp. 79-82, pp. 133-136, pp. I45-156; Guy Hennebelle, «Un cinéaste français au service du FLN: René Vautier», CinémAction, no 85 (Guy Hennebelle, éd., «La guerre d'Algérie à l'écran»), 1997, pp. 158-159. Voir aussi l’article de Sébastien Layerle, dans le présent dossier.

3 Voir, par exemple, la profession de foi de Dominique Dubosc, qui a tourné à l'intérieur de l'usine Lip occupée par les ouvriers: «On peut sans doute dire qu'il y a une dimension politique dans l'art, ou dans certaines ouvres d'art, mais pas l'inverse: les films militants [...] n'ont pas grand chose à voir avec le cinéma en tant qu'art. En revanche, je crois qu'ils ont tout à voir avec la politique, c'està-dire qu'ils doivent être rigoureusement insérés dans une action politique.» (Christine Martin, «Faire voir, ceci et rien d'autre. Entretien avec Dominique Dubosc ", La Lettre du cinéma, $\mathrm{n}^{\circ} 28$, automne 2004, repris en ligne sur le site www.dominiquedubosc.org).

4 Voir René Vautier, Caméra citoyenne, op. cit., p 5r. Rappelons également la fondation en 1978, en France, du Mouvement

\section{René Vautier et le cinéma ouvrier: I'UPCB, une structure de production au service des « colonisés de l'intérieur »}

LE CINÉMA MILITANT EST LE PLUS SOUVENT marqué au sceau de l'internationalisme, le cinéaste intervenant au sein de luttes armées pour l'indépendance ou s'engageant dans des conflits sociaux ancrés dans des situations géopolitiques déterminées. C’est exemplairement le cas de Joris Ivens, que René Vautier considère comme un modèle et un point de repère: le cinéaste prend activement part aux luttes d'indépendance et aux mouvements de grève, en s'impliquant concrètement sur le terrain. Ivens peut ainsi exalter la lutte des Républicains et dénoncer les exactions des franquistes dans Terre d'Espagne (1937), filmer la grève des dockers et des marins indonésiens s'insurgeant contre la colonisation dans Indonesia Calling (1946), ou encore le processus de décolonisation des Maliens dans Demain à Nanguila (1960) 1'. Quant à René Vautier, il stigmatise la situation coloniale en Afrique-Occidentale française dans Afrique 50 (I950) et l'apartheid en Afrique du Sud dans Frontline (réalisé avec Oliver Tambo, I976), ou encore tourne auprès des militants indépendantistes pendant la guerre d'Algérie (notamment Une nation, l'Algérie, 1954, Algérie en flammes, 1957-1958, et Un peuple en marche, 1963) tout en formant les opérateurs du Centre audiovisuel d'Alger, qu'il dirige de 1962 à 1965 ${ }^{2}$. Il s'agit là de films «insérés» dans une lutte ${ }^{3}$, ou de «cinéma d'intervention sociale» pour reprendre l'expression revendiquée par René Vautier ${ }^{4}$.

\section{De l'usage du film militant comme porte-voix}

Dans la France des années i968, plusieurs prises de position s'affrontent sur la fonction des films militants, leurs modalités de production, leurs

audio-visuel d'intervention (MAI), qui témoigne d'une volonté de fédération et de coordination du cinéma et de la vidéo d'in- tervention sociale et politique (voir Guy Hennebelle, «L'impact du troisième cinéma», Tiers-Monde, vol. 20, n ${ }^{\circ}$ 79, p. 644). 
formes d'écriture, leur circulation et leur destination. René Vautier se situe sans aucune ambiguïté au sein de ces débats, sa participation au cinéma militant remontant par ailleurs à la fin des années i940 déjà. Dans une perspective diamétralement opposée à la logique auteuriste et à l'affirmation d'un cinéma de la «distanciation» qui constituent l'un des modèles de référence dans les années i96o, Vautier s’oppose aux pratiques qui visent à déconstruire les modes de représentation dominants, et que l'on pourrait décrire rétrospectivement comme répondant à une «idéologie de la forme». Si l'on admet, à la suite de David Faroult ${ }^{5}$, qu'il faut opérer une distinction entre les films pensés comme le reflet d’une lutte sociale et les films développant une forme révolutionnaire ou, si l'on préfère, les démarches non marquées stylistiquement qui accordent le primat au message à véhiculer - à l'image du collectif Cinélutte - et les gestes de déconstruction du caractère idéologique du langage cinématographique - à l'instar du groupe Dziga Vertov -, force est de constater que René Vautier, et avec lui l’Union de Production Cinéma Bretagne (l'UPCB), prennent résolument parti pour le premier modèle: à savoir un cinéma de la «contre-information», dans le but de toucher le public le plus large possible. Explicitons ces politiques de production et diffusion divergentes. Godard, grâce à la valeur d'échange symbolique de sa signature, obtient le soutien de la télévision pour produire les films du groupe Dziga Vertov, mais ne se préoccupe guère de leur diffusion, ceux-ci étant par ailleurs systématiquement interdits d'antennes sur les chaînes qui en sont pourtant les commanditaires (conformément à la logique de la commande détournée) ${ }^{6}$. Vautier, faisant appel à des souscriptions ouvrières et au soutien de structures syndicales pour produire ses films, ne se limite pas aux réseaux militants (comités d'entreprise, comités d'action, associations syndicales, lycées, universités, maisons des jeunes), mais vise à obtenir une distribution commerciale, une reconnaissance dans les festivals et une diffusion à la télévision.

Ces débats ne se limitent pas à Mai 68 et aux Etats généraux du cinéma en France ${ }^{7}$, mais se posent encore avec vivacité des décennies plus tard, comme une table ronde entre Godard et Vautier, organisée par «Les

5 «Pendant et après mai ig68 une orientation domine dans les pratiques cinématographiques qui se veulent $\ll$ mi- litantes $>$ : filmer les luttes. [...] Le collectif le plus représentatif en est peut-être $\mathrm{Ci}$ nélutte [.... [...] Le mot d'ordre du groupe
Dziga Vertov (‘faire politiquement des films politiques `) doit être compris d'abord comme le premier aboutissement d'une recherche (le mûrissement des expériences brechtiennes des années 6o), mais il faut également le restituer dans sa vigueur polémique, comme l'exigence d'une conscience de sa propre démarche contre celles, déjà évoquées, de la 〈fiction de gauche〉 et de certaines tendances du 〈cinéma militant〉. [... 〈 Faire politiquement des films〉, c'est aussi se poser politiquement la question de leur production. De ce point de vue, le groupe Dziga Vertov défend un point de vue marginal: celui du primat de la production. [...] on peut dire que la démarche du groupe Dziga Vertov s'oppose radicalement à celle des groupes tels que Cinélutte: il ne s'agit pas de rendre compte d'un mouvement, mais d'analyser des situations et, en les analysant, de donner au spectateur des outils pour analyser d'autre situations.» (David Faroult, «Quelles résistances au cinéma dominant?», dans David Faroult et Gérard Leblanc, Mai 68 ou le cinéma en suspens, Tarascon/Paris, Festival Résistances/ Syllepse, I998, pp. Io-II, pp. I7-I9).

6 Surlegroupe Dziga Vertov (I969-I973), voir notamment Antoine de Baecque, Godard: biographie, Paris, Grasset, 20ıо, pp. 443-5i6.

7 Voir Le Cinéma s'insurge: états généraux du cinéma, $\mathrm{n}^{\circ} \mathrm{I}^{-3}$, I968. René Vautier ne prend pas directement part au cinéma de Mai 68 (il collabore néanmoins à Classe de lutte, premier film revendiqué par le groupe Medvedkine, à Besançon, en r968); pendant les Etats généraux de Suresnes, il travaille au Sahara pour la télévision algérienne. 
8 Voir Jean-Luc Godard, René Vautier, « ¿Au nom des larmes dans le noir». Echange sur l'histoire, l'engagement, la censure» (4 novembre 2002), dans Nicole Brenez, David Faroult, Michael Temple, James E. Williams, Michael Witt (éd.), Jean-Luc Godard. Documents, Paris, Centre Pompidou, 2006, pp. 398-405.

9 Voir "Cinémas de rupture», Ecran, $\mathrm{n}^{\circ} 65$, janvier 1978 (rencontre organisée en novembre I977 par «Cinéma politique»). Une seconde rencontre a lieu à Rennes, en novembre I978, organisée par «Cinémarges». A noter encore: les Journées du cinéma militant de la Maison de la culture de Rennes, en 1977 et I978 (René Vautier y a-t-il pris part?).

10 «Cinémas de rupture: le point de vue de René Vautier», Ecran, n 66 , février 1978 , p. 70 .

11 Certes, comparaison n'est pas raison; mais sur le plan énonciatif, le programme de Vautier et de l'UPCB est à situer du côté du «Surréalisme au service de la révolution», en aucun cas d'une «Révolution surréaliste», pour renvoyer à un précédent historique où l'opposition entre «révolution des formes» et «expression au service de la révolution» se joue en des termes véhéments (voir $L a$ Révolution surréaliste, 1924-1929; Le Surréalisme au service de la révolution, I930I933). Précisons toutefois que le surréalisme ne semble pas constituer une référence cruciale pour Vautier. écrans citoyens ", s'en fait le lointain écho en $2002^{8}$. Pour s'en tenir à la période qui retient ici notre attention, en lien avec les activités de l'UPCB, un épisode nous paraît crucial quant à ce qui se joue dans le cinéma militant des années i970, en l'occurrence une rencontre (connue sous le nom de «colloque de Saint-Charles») qui a pour enjeu de définir les «cinémas de rupture ${ }^{9}$, organisée à Paris par les collectifs du cinéma militant et du cinéma différent en novembre I977 - l'opposition entre diffusion et écriture militantes se déclinant, quelque dix ans après le renoncement à la réalisation d'un «film de synthèse», entre partisans du cinéma militant et tenants du cinéma expérimental (en l'occurrence, l’Association des cinéastes indépendants, différents et expérimentaux). Si René Vautier n’a pas pris part à cette table ronde, il a par contre exprimé sans équivoque son point de vue sur le sujet, dans le numéro de février 1978 de la revue Ecran. A la question: «quoi mettre au poste de commandement de nos films, la forme ou le contenu, c'est-à-dire l'esthétique ou la 〈politique〉», qu'il dénonce d'emblée comme «aberrante» et «dépassée», il substitue l'interrogation suivante, portant sur l'acte d'énonciation d'un film militant: «qui mettre au poste de commandement de nos films, qui doit les inspirer, qui doit les contrôler, qui doit s'y exprimer?» ${ }^{10}$ Rejetant la «télévision française» et la «classe dominante» (passons sur l'amalgame par trop facile qu'il opère entre l'ORTF et le groupe Dziga Vertov), il y répond en affirmant une confusion ou, pour le dire plus positivement, une homologie entre les places du destinataire, du commanditaire et du réalisateur de films militants:

«[...] ceux qui doivent s'exprimer dans nos films, ce sont ceux à qui l'on prétend interdire l'expression - les exploités. [...] Et c'est avec eux que nous déterminons comment utiliser tout cela - pour utiliser le mot, sous quelle 〈forme` nous allons présenter leur vision des choses.»

Le mot d'ordre, le credo, ici, est celui du cinéma «mis au service de la révolution ${ }^{11}$, le cinéaste endossant le point de vue de l'ouvrier. Vautier poursuit son argumentaire à travers une critique virulente du "phénomène Nouvelle Vague», dénoncé comme une simple «chapelle bourgeoise»:

«Les petits jeunes mal à l'aise, mal dans leur peau, ont cherché - sans se couper radicalement du cinéma de papa - à faire bande à part, à aménager un coin pour eux, une 〈expression` qui leur soit propre. [...] Je vois venir ceux d'ici qui savent que je suis communiste: ah, ah, disent-ils en se frot- 
tant les mains, mais c'est Aragon qui a encensé Godard et a clamé son génie. Hé oui, il est peut-être temps de le dire: Aragon a la même origine que Jean-Luc Godard, c'est tout. Il est peut-être plus capable de reconnaître du génie à un Jean-Luc Godard que de comprendre pleinement un ouvrier parlant de ses problèmes à l'usine. Et je pense aujourd'hui qu'il est important que, grâce à l'image et au son, l'ouvrier d'usine (ou le paysan) puisse parler de lui-même et de ses problèmes sans passer par scribe interposé. Et c'est ce que nous entendons faire: leur donner les moyens de parler eux-mêmes de la réalité de leur vie, les donner à tous ceux qui vivent l'histoire d'aujourd'hui et à qui le pouvoir met un bâillon.» ${ }^{12}$

La charge est polémique. Mais Vautier réaffirme là sa profession de foi, à savoir l'expression d'un point de vue populaire, qu'il présente comme antagoniste avec «l'invention d'une « forme révolutionnaire à imposer [...] à l'expression ouvrière». Le but de l'UPCB, c'est de se faire le porte-parole des opprimés et des révoltés qui n’ont pas accès aux moyens de communication de masse:

«Tout bêtement se mettre à la disposition de ceux qui luttent, leur faire savoir qu'il y a là, dans nos mains, mais prêtes à être utilisées par eux, des armes d'expression. Et puis aussi, leur apprendre à s'en servir, pour qu'ensuite ils puissent le faire sans nous. C'est là toute la ‘conception UPCB) du cinéma militant, pour l'instant. [...] Et s'il faut résumer notre position: une esthétique neuve naîtra de la nécessité d'expression de classe, c'est-à-dire de la mise à la disposition d'une classe opprimée des moyens d'expression monopolisés jusqu'ici par la classe dominante.» ${ }^{13}$

On voit ici à nouveau affleurer l'opposition entre le primat accordé à la diffusion des films militants et l'affirmation d'une écriture révolutionnaire («faire politiquement des films politiques», selon la formule choc de Godard). Soutenir que le cinéma militant est un porte-voix, un hautparleur des masses populaires et ouvrières, c'est se situer en porte-à-faux avec la conception du film comme tableau noir, revendiquée par Godard en i969:

«Pendant la projection d'un film impérialiste, l'écran vend la voix du patron au spectateur: la voix flatte, réprime ou matraque. Pendant la projection d'un film révisionniste, l'écran est seulement le haut-parleur d'une voix déléguée par le peuple mais qui n’est plus la voix du peuple, car le peuple regarde en silence son visage défiguré. Pendant la projection d'un film militant, l'écran est simplement un tableau noir ou un mur d'école qui offre l'analyse concrète d'une situation concrète...» ${ }^{14}$
12 "Cinémas de rupture: le point de vue de René Vautier », op. cit., p. 70.

13 Id., pp. 70-7i. René Vautier réaffirme ce point de vue à l'occasion d'une table ronde la même année: «Je voudrais comme d'habitude jouer au provocateur et demander à Fernando quel public il avait en tête en tournant Les Heures des brasiers: le public de gauche des sociétés européennes industrialisées ou le public argentin? La question me paraît importante dans ce débat que nous entamons sur le thème: quel cinéma politique aujourd'hui? Quel intérêt présenterait, en effet, un cinéma politique qui ne serait pas susceptible d'intervenir dans les luttes immédiates, concrètes, populaires? Etant entendu que ce cinéma politique peut fort bien être de type historique ou de science-fiction.» ("Cinéma d'auteur ou cinéma d'intervention? Table ronde avec Fernando Solanas, Bertrand Tavernier, René Vautier et Guy Hennebelle», Ecran, numéro hors-série, mai i978, p. 6o).

14 Jean Luc Godard (pour le Groupe Dziga Vertov), «Premiers sons anglais», Cinéthique, $\mathrm{n}^{\circ}$ 5, septembre-octobre 1969 , repris dans Jean-Luc Godard par JeanLuc Godard, tome I: I950-I984, Paris, Cahiers du Cinéma, I998, p. 338. 
15 Voir Jean-Louis Baudry, «Effets idéologiques produits par l'appareil de base», Cinéthique, $\mathrm{n}^{\circ}$ 7-8, I970, pp. I-8. Cet essai prolonge les propos de Marcellin Pleynet (Jean Thibaudeau, «Economique, idéologique, formel: entretien avec Marcellin Pleynet», Cinéthique, $\mathrm{n}^{\circ} 3$, I969, pp. 8-I4), qui visent à déconstruire le dispositif cinématographique et le caractère idéologique du mode de représentation dominant. Cet appel à la reconfiguration des codes de langage du cinéma, au centre du programme du groupe Dziga Vertov ou de Cinéthique, peut être envisagé comme un nouveau formalisme lorsqu'il est absolutisé et retranché de la base à laquelle on entend pourtant s'adresser.

16 P.A.P., «Féminisme et luttes sociales: «Quand les femmes ont pris la colère», un film de Soazig Chappedelaine», Rouge, 9 novembre 1977.

17 René Vautier, «Insérer notre action générale dans un cinéma français qui se cherche» (propos recueillis par Gérard Langlois), Cinéma, n I63, février I972, p. 77.

18 René Vautier définit en ces termes les «axes de production» de l'UPCB: «D'abord un regard breton sur le monde; faire des films d'analyse aussi bien sur la situation en Rhodésie que sur le pétrole en Algérie, sur la réforme agraire au Pérou ou sur les luttes ouvrières en Suède. Deuxième axe: aider, à l'échelon de la Bretagne, tous ceux qui veulent faire quelque chose à l'échelon local ou régional, par le cinéma ou l'audio-visuel. Troisième axe: renforcer sur place, en Bretagne, l'équipe permanente de journalistes, d'opérateurs, de monteurs, d'ingénieurs du son, former des stagiaires et garder en état de marche un «instrument > permettant de produire et diffu-
Contre la conception didactique («tableau noir») ou "formaliste» (déconstruction de «l'appareil idéologique de base» ${ }^{15}$ ) du cinéma militant, l'UPCB entend littéralement mettre sa caméra au service des «colonisés de l'intérieur», de leur point de vue, sans pour autant renoncer à tourner et à assumer eux-mêmes des prises de vues orientées. Dans cette perspective collectiviste, la notion d'auteur devient elle-même suspecte, comme le soutient Vautier:

«Le film d'auteur est une parcelle de liberté à l'intérieur du cinéma commercial, mais ça reste dans le cadre d'un système bourgeois. [...] A l'UPCB, nous élargissons la notion d'auteur, vers une responsabilité collective de création. Nous sommes un haut-parleur, un instrument technique pour que la base puisse s'exprimer dans ses luttes.» ${ }^{16}$

\section{L'UPCB, « du colonialisme au socialisme »}

L'UPCB est une société à responsabilité limitée (SARL), fondée en I969 par Vautier, Nicole et Félix Le Garrec, près de Quimper. La vente d'un scénario de Vautier à un cinéaste argentin, qui donnera lieu à Des goûts et des couleurs (Juan Battle Planas, I970) ${ }^{17}$, permet de financer la société, qui se consacrera à la production, à la réalisation et à la diffusion de films militants tant sur un plan régional (avec et pour les «colonisés de l'intérieur») qu'international (Yves Billon, par exemple, réalise un film sur l'opposition des paysans d'Amazonie à la construction d'une route transamazonienne) ${ }^{18}$. A défaut de les analyser et de les commenter, contentons-nous de citer les principales productions de l'UPCB. René Vautier réalise à travers cette structure les films suivants: Les Ajoncs (avec Mohamed Ziné, I970), Les Trois Cousins (avec Mohamed Ziné, I970), La Caravelle (1970), Techniquement si simple (1971), Mourir pour des images (1971), Avoir 20 ans dans les Aurès (1972), Transmission d'expérience ouvrière (1973), La Folle de Toujane (avec Nicole Le Garrec, I974), Quand tu disais Valéry (avec Nicole Le Garrec, 1975), Alan Stivell (1976), Frontline (avec Oliver Tambo, I976), Quand les femmes ont pris la colère (Soazig Chappedelaine, I977), Le Poisson commande (1978), Marée noire, colère rouge (1978), Vacances en Giscardie (1980), Le Scorpion de Saint-Nazaire (I980), Déjà le sang de mai ensemençait novembre (1982). Serge Poljinsky

ser des longs métrages.» (Marcel Mettey, «Avoir vingt ans dans les Aurès», Image I974, p. 23). 
réalise Liberté au féminin (1974) et Le Funambule (1974); Maria Koleva La Fête aujourd'hui, la fête demain (1974); Philippe Cassard Terra Corsa (I974); Dominique Bloch, Philippe Haudiquet et Isabelle Lévy Gardarem lon Larzac (I974); Yves Billon De sol à sol (I977). Cette articulation entre le national et l'international est définitoire des tâches de l'UPCB:

«[...] l'UPCB se veut d'abord au service de la Bretagne et par extension au service de ceux qu'elle appelle «les colonisés de l'intérieur `. [...] Son catalogue porte en sous-titre: 〈Du colonialisme au socialisme〉. L'UPCB s'efforce, non sans succès, de faire pénétrer le cinéma militant dans les structures de diffusion commerciale. ${ }^{19}$

Le primat de la diffusion sur la production se signale ici à travers la recherche d'une distribution commerciale, ambition qui ne sera que partiellement atteinte - le propos proche du brûlot politique mais aussi la forme brute de ces films contrevenant à leur commercialisation, à l'exception d'Avoir 20 ans dans les Aurès (I972, prix de la critique internationale au festival de Cannes) et de La Folle de Toujane (I974) qui ne connaît pourtant pas un succès critique et public comparable. Nous pouvons par ailleurs soutenir que la diffusion non commerciale peut avoir autant d'impact et d'échos que la distribution en salle - c'était par ailleurs déjà là la conclusion à laquelle arrivait John Grierson à la fin des années I920, alors à la tête du GPO Film Unit ${ }^{20}$.

En un sens, ce rôle prépondérant accordé à la diffusion se matérialise à travers Transmission d'expérience ouvrière (I973): si ce film est pris en charge par les militants, il est lui-même conçu comme un objet d'échange et de relais, un pur acte de transmission destiné à l'espace public ouvrier. Comme le précise Vautier, ce film «a été financé par les ouvriers des forges d'Hennebont qui souhaitaient expliquer aux grévistes de Lip comment éviter les erreurs dans lesquelles pour leur part ils étaient tombés. C'est à cette fin qu'ils nous ont donné trois mille nouveaux francs pour faire ce court métrage strictement militant. ${ }^{21}$ Comme le laisse entendre Guy Hennebelle, la matérialité du film est déniée ou dépassée à travers sa mise en circulation dans une ère d'échange de paroles, comme si les ouvriers d'Hennebont s'adressaient directement, sans médiation, à ceux de Lip:

«Dans ce court métrage d'un quart d'heure, René Vautier a donné la parole aux ouvriers des forges d'Hennebont, en Bretagne, qui expliquent à l'intention des ouvriers de Lip (alors en occupation de leurs locaux)
19 «U.P.C.B.: Faire prendre conscience que les choses doivent nécessairement changer», Cinéma d'aujourd'hui, nº 5-6 (Guy Hennebelle, éd., «Cinéma militant: histoire, structures, méthodes, idéologie et esthétique»), mars-avril ı976, p. 73. Précisons que Vautier et Nicole Le Garrec marquent leur différence de positionnement politique: «L'UPCB n'est pas rattachée à un parti. Pour René Vautier, militant communiste, elle est au service des masses organisées. Pour Nicole Le Garrec, elle est d'abord au service des aspirations des gens.»(ibid.).

20 John Grierson réalise en I929 Drifters, un moyen métrage sur la pêche au hareng; ce film, dont les coûts de production étaient modestes, remporte un large succès, à la différence de One Family, long métrage de fiction scénarisé par Rudyard Kipling qui s'avère être un gouffre financier et constituer une erreur de goût selon les critiques de l'époque. Grierson, qui dirige le GPO Film Unit, renonce rapidement à la distribution commerciale (après l'expérience de «The Industrial Six», moyens métrages diffusés par Gaumont British, avec une sonorisation plaquée arbitrairement sur les films), pour développer un large réseau éducatif, culturel et gouvernemental. Sur ce point, voir Scott Anthony et James G. Mansell (éd.), The Projection of Britain: A History of the GPO Film Unit, Basingstoke, Palgrave Macmillan, 20II.

21 «U.P.C.B.: Faire prendre conscience que les choses doivent nécessairement changer», op. cit., p. 74 . 
22 Guy Hennebelle, «Transmission d'expérience ouvrière», Ecran, $\mathrm{n}^{\circ} 45$, mars i976, p. 76. Hennebelle est plus critique sur la forme de ce court métrage: «Du point de vue esthétique, le film a peut-être le tort de montrer un peu trop de manifestations et de défilés à son début mais très vite le propos se resserre et accroche. D'autant que Vautier a eu la bonne idée de remplacer la plupart du temps la pratique surannée du commentaire didactique par sa propre voix qui explique sur le ton de la conversation quotidienne ce qui se passe sur l'écran, un peu comme on commente en famille un film de vacances en Super 8 !».

23 "C'est pourquoi nous avons demandé aux ouvriers de Trignac près de Saint-Nazaire de trouver ro ooo personnes d'accord pour payer à l'avance leur place pour que nous puissions tourner Quand tu disais Valéry et rendre compte de leur grève. Ils ont trouvé ces dix milles (commanditaires > et nous, les crédits labo, et c'est comme ça que nous avons pu réaliser ce troisième long métrage.» («U.P.C.B.: Faire prendre conscience que les choses doivent nécessairement changer», op. cit., p. 75).

24 Guy Hennebelle, "Quand tu disais, Valéry... », Ecran, n ${ }^{\circ}$ 44, février 1976 , p. 64. Quand tu disais Valéry est tout d'abord destiné à la diffusion militante; en un second temps, il sera exploité en salle: «Malgré une diffusion en circuit commercial, ce film ne peut pas être considéré comme n’importe quel film. Sa principale diffusion, il l'a connue dans les entreprises, il a alimenté des discussions, il a amorcé des prises de conscience. Ce n'est pas un spectacle, mais un film d'intervention, destiné à aider les luttes des travailleurs [...].» (Guy

comment ils ont été floués par les promesses patronales et autres. [...] Aussi engagent-ils, au travers de ce film, les Lip à ne pas se laisser ‘avoir > par les belles paroles que l'on ne manquerait pas de leur prodiguer. C'est donc une expérience tout à fait inédite dans le cinéma, au moins français, que René Vautier a tentée (et semble-t-il réussie) avec ce filmavertissement.» 22

«Film-avertissement», Transmission d'expérience ouvrière se substitue à l'acte de médiation et à la prise de parole: il fait le relais entre deux luttes ouvrières, véhiculant directement des directives et un plan d'action. Tout se passe ici comme si c’était la lutte qui était «insérée» dans le film, celui-ci se substituant à la discussion, devenant ainsi le lieu même du débat.

Dans tous les cas, le «cinéma ouvrier» constitue l'un des fers de lance de l'action de l'UPCB, comme nous allons nous attacher à l'exposer à travers l'analyse de deux longs métrages.

\section{"Quand tu disais Valéry », ou comment «filmer de l'intérieur »}

Quand tu disais Valéry (Nicole Le Garrec et René Vautier, I975, I40 min) est composé de cinq courts métrages, de 25 à 30 minutes, qui ont également été présentés de façon autonome: «Vivre à Trignac», «Il n’y a pas de bon patron», «La vie d'ouvrier», «Le changement et la continuité», «Nos libertés et leur justice». Produit à travers le Centre de Culture populaire de Saint-Nazaire et la souscription des ouvriers de Trignac ${ }^{23}$, ce long métrage connaît une diffusion militante - chaque épisode étant projeté "pendant la pause de midi dans les usines» ${ }^{24}$, Hennebelle estimant en mai 1976 le public à quarante mille spectateurs ${ }^{25}$ - mais égale-

Gauthier, "Quand tu disais, Valéry», Image et son, $\mathrm{n}^{\circ} 77$, octobre 1977 , p. 230). 25 «Le titre du film donne une idée assez juste de son contenu: les auteurs, cinéastes et ouvriers, l’ont apparemment conçu comme une brutale apostrophe envers les responsables de la situation d'insécurité dans laquelle vit aujourd'hui une grande partie des salariés en France et, par-delà le patronat et l'administration locale, ils interpellent l'actuel président de la République [...]. En attendant, il a été déjà été vu par quarante mille spectateurs dans de nombreuses usines (ainsi que dans plusieurs villes étrangères: Amsterdam, Alger, etc.). Pour faciliter sa présentation durant la pause de midi, il a été délibérément conçu en cinq parties [...].» (Guy Hennebelle, «Quand tu disais Valéry... L'intérieur du combat», Le Monde diplomatique, mai i976). 
ment commerciale ${ }^{26}$. Les bénéfices des entrées permettront de financer Quand les femmes ont pris la colère.

René Vautier est on ne peut plus explicite quant à la fonction de ce film, qui émane littéralement d'une commande sociale:

«Nous nous sommes contentés de suivre les événements en étant seulement un outil technique entre les mains des ouvriers de Trignac. Ce que nous avons essayé de faire, c'est laisser les ouvriers créer leurs images, les habiller de leurs propres mots. [...] Jamais l'expression ‘filmer de l'intérieur $>$ ne fut si justifiée. [...] ${ }^{27}$

Le film combine des images et des sons produits directement par les ouvriers ${ }^{28}$ - conformément au programme des groupes Medvedkine ${ }^{29}$ à des séquences tournées majoritairement par Pierre Clément lors de manifestations, dans l'usine ou dans l'intimité des travailleurs. Le dossier de presse de l'UPCB confirme cette vocation à «filmer de l'intérieur» ou à «investir» l'espace public ouvrier:

«L'histoire de la SEMM-SOTRIMEC n'est pas unique. Mais la possibilité existe de faire un film unitaire CGT et CFDT tendant à rassembler les travailleurs dans la lutte. Il s'agit de faire non pas un film de propagande, mais un film d'analyse sur la situation de luttes ouvrières et syndicales d'aujourd'hui, donner une image actuelle d'un combat, pour que cette image enrichisse ceux qui en mèneront demain. [...] Les cinéastes de l'UPCB ont vécu parmi les travailleurs et leur famille. Le résultat: des kilomètres de pellicule, de bandes sonores à visionner, écouter, choisir, ordonner. Quatre mois de dialogues, de discussions, de heurts, de joies, de la salle de montage parisienne à l'usine de Trignac pour raconter ensemble une histoire.» ${ }^{30}$

Suite au générique, qui alterne entre la chanson «Quand tu disais, Valéry, que ça changerait, Valéry, nous on savait, Valéry, que c'était de la blague», interprétée par les Gallouest, et des caricatures ou des interventions télévisées de Giscard d'Estaing, René Vautier présente la situation de crise que traverse la ville de Trignac. Ces séquences d'exposition, enchaînant les panoramiques en cadrage large sur la ville de Trignac en l'absence de toute activité humaine, s'ouvrent sur un symbole de la lutte des ouvriers de Trignac: une caravane construite autour d'un arbre, pour marquer l'ancrage de l'usine dans ce territoire. En contreplongée, l'opérateur filme caméra à l'épaule le haut d'un arbre dépourvu de feuilles, avant de descendre sur la caravane, où est inscrit en lettres
26 Précisons encore que Quand tu disais Valéry est sélectionné en I976 au festival de Cannes (section Perspectives du cinéma français) et classé meilleur film français au festival de Rotterdam.

27 Robert Grelier, "Quand tu disais, Valéry», Image et son, $\mathrm{n}^{\circ}$ 306, mai 1976 , p. 92.

28 «En effet, à l'origine pour impulser le développement des activités culturelles, le comité d'entreprise avait mis à la disposition des organisations syndicales, des moyens techniques qui ont permis de photographier, filmer, enregistrer tous les événements marquants de la grève. C'est ainsi que les réalisateurs récoltèrent: films en super-8, cassettes sonores, tracts, lettres officielles de la direction, témoignages vivants reflétant quotidiennement avec beaucoup d'acuité une lutte qui dura pendant plus d'un an, et menée à l'échelon d'une région.» (Robert Grelier, «Quand tu disais, Valéry», op. cit., p. 92).

29 Sur le groupe Medvedkine, voir Bruno Muel, «Les riches heures du groupe Medvedkine (Besançon-Sochaux I967-I974), Images documentaires, $\mathrm{n}^{\circ}$ 37-38 («Parole ouvrière»), 2000, pp. 15-35.

30 Dossier de presse de l'UPCB, Fonds Jean-Pierre Jeancolas, Section d'histoire et esthétique du cinéma, Université de Lausanne. Nos remerciements vont à Sylvain Portmann pour nous avoir communiqué ce dossier. 


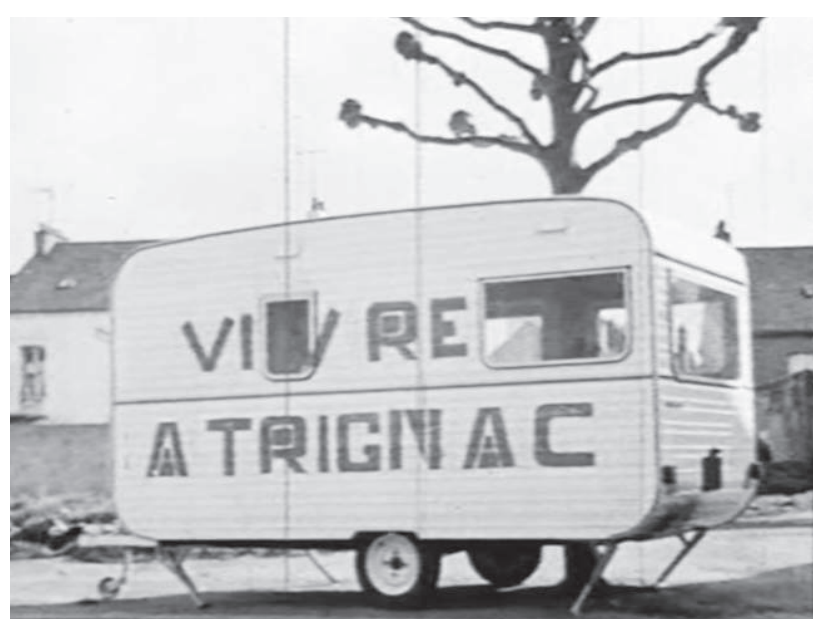

rouges «Vivre à Trignac», pour finalement opérer un zoom arrière réinscrivant la caravane dans l'espace urbain. En voix over, René Vautier déclare: «Ici aujourd'hui, même les arbres ont l'air de serrer les poings ». L'incipit du film est ainsi construit autour de la trace d'un geste militant de la part des ouvriers, résistance qui semble vouée à l'échec mais qui perdure, à l'image du platane, dont les branches élaguées peuvent évoquer des poings levés. Le commentaire de René Vautier, dans les plans descriptifs qui suivent, présente avec une distance sarcastique le vide et l'inactivité qui ont gagné la ville de Trignac, après la fermeture de l'usine (ainsi, par exemple, de «Mademoiselle le facteur» dont le principal rôle aujourd'hui semble se réduire à distribuer des lettres de licenciement). Vautier en voix over revient sur l'essor industriel de Trignac et la fermeture des usines de fonderie au XIX ${ }^{\mathrm{e}}$ siècle et au début $\mathrm{du} \mathrm{XX}^{\mathrm{e}}$ siècle, soulignant la conscience ouvrière de la population et les exactions auxquelles elle a dû faire face. Dans cette première partie, les manifestations sont également saisies sur le vif, Vautier soulignant sur la bande son la continuité des luttes ouvrières, de génération en génération. Recourant par la suite à la pratique de l'interview filmée (dans un tabac qui a dû renoncer à la plupart de ses employés, dans une boulangerie, sur la place du marché), il prend la mesure des consé- 
quences de la fermeture de l'usine sur les commerçants et les habitants de la bourgade.

La deuxième partie, directement supervisée par René Vautier, s'ouvre sur la lecture d'un rapport intitulé Pour un nouveau management de l'entreprise (Cycle de conférences à l'usage des chefs d'entreprise), exposant les stratégies du patronat. Cette partie est centrée sur un long entretien avec un délégué de la CGT et un délégué de la CFDT qui reviennent sur les stratégies du patron qui a repris l'entreprise Caravalair - ce qui a conduit Guy Hennebelle ${ }^{31}$ à critiquer la dimension unilatéralement propagandiste du film, celui-ci se faisant directement le porte-parole du discours syndical (au point même, cela mérite d’être relevé, que les propos du cégétiste semblent par instants se substituer à la voix over de Vautier ou du moins, sa prise de parole occupe une fonction et une position analogues). Cette partie, qui se penche sur les manœuvres du patron Trigano, propose, à travers une analyse historique et politique des faits, un décryptage de la situation (direction participative de l'usine par l'objectif suscitant des divisions, répression syndicale, restructuration des activités de l'usine, et enfin licenciement des travailleurs avec la délocalisation de l'entreprise dans l'Ardèche), tout en soulignant l'organisation de la lutte syndicale. Vautier donne également la parole à plusieurs ouvriers et ouvrières, tout en filmant les activités à l'intérieur de l'usine occupée.

La troisième partie, «La vie d’ouvrier», supervisée par Nicole Le Garrec, recueille les réactions d'ouvriers et d'ouvrières dans la région de la Brière, sans que ceux-ci ne fassent allégeance à un parti ou un syndicat déterminé, et tente de restituer au plus près leurs conditions de vie. A la différence du point de vue analytique et vindicatif des autres parties, le film se recentre sur le quotidien des familles ouvrières, à travers des témoignages recueillis le plus souvent à leur domicile (portant sur les conditions de logement, le faible pouvoir d'achat, etc.). Cette partie se recentre par la suite sur l'occupation de l'usine, se concluant par un gala de solidarité organisé par les ouvriers de Trignac.

Les deux dernières parties, que l'on peut imputer à Vautier, articulent luttes ouvrières (manifestations, occupation de l'usine et séquestration du patron, répression des CRS) et analyse des rapports de force politique, impliquant également et très directement l'équipe de réalisation du film. Des plans d'une manifestation à Saint-Nazaire et
31 Guy Hennebelle, qui salue pourtant là «l'un des films français les plus intéressants de ces dernières années", regrette le «caractère largement révisionniste» de Quand tu disais Valéry: le film, au lieu de «dénoncer la trahison, de plus en plus fréquente, de certaines directions syndicales lors des conflits ouvriers et autres, exalte au contraire [...] l'unité d'action entre la CGT et la CFDT». Pour Hennebelle, le film a pour «but de suggérer aux spectateurs qu'il faut toujours faire confiance aux directions syndicales, notamment à la CGT, et s'en remettre à elles corps et âme.» (Guy Hennebelle, "Quand tu disais, Valéry...», Ecran, ${ }^{\circ} 44$, février 1976, p. 64). 

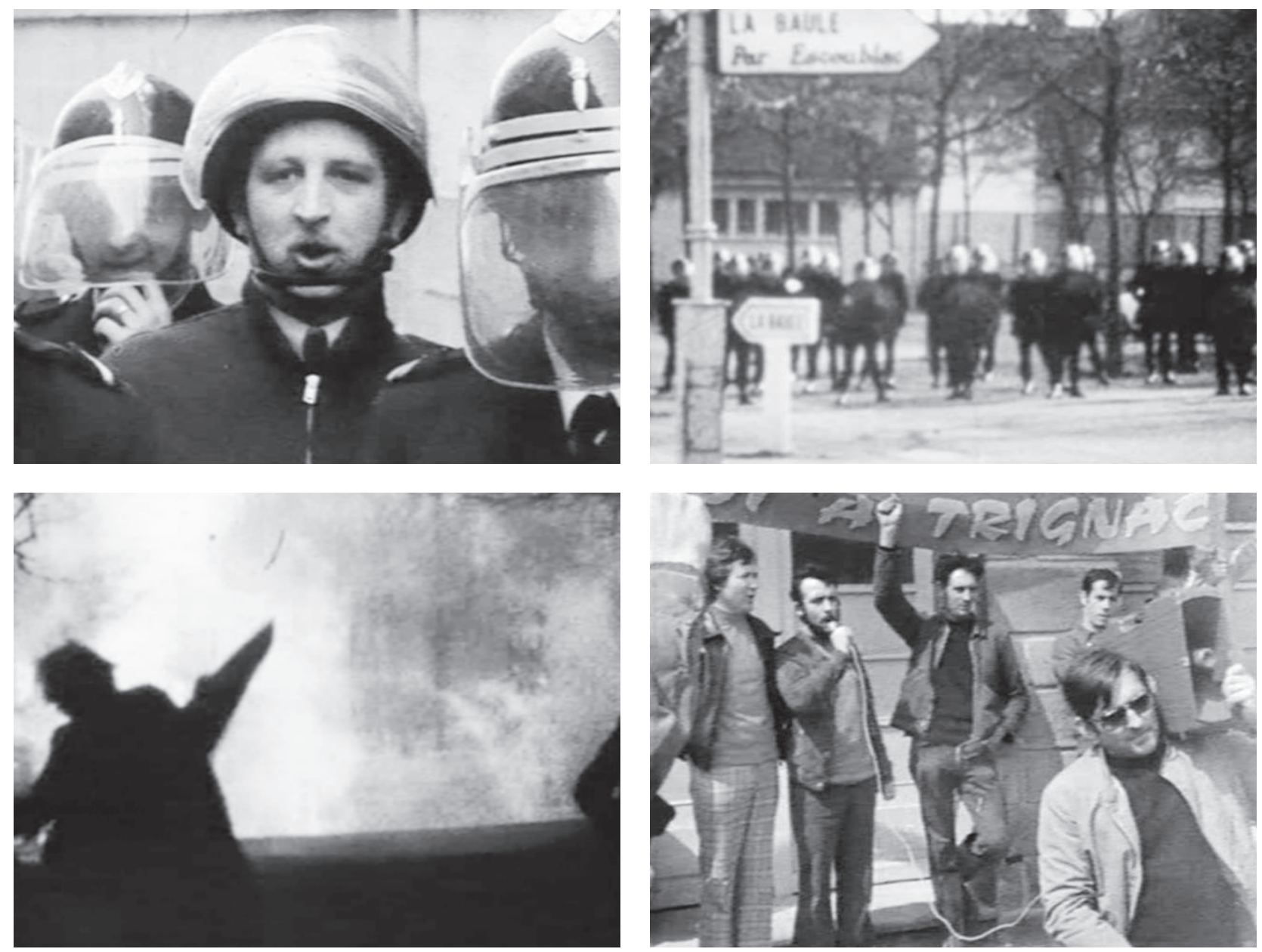

de sa répression violente par les CRS constituent l'une des séquences les plus prégnantes du film, incarnant la logique du «manifestant filmant», l'urgence de la prise de paroles et le débordement de véritables scènes de guérilla urbaine. L'interaction entre l'acte d'insurrection et l'équipe de tournage concourt à la performativité de ce témoignage politique, qui constitue un véritable tour de force (la caméra 
«participante» ${ }^{32}$ de l'opérateur s'oppose aux forces de l'ordre, fait face à la matraque et aux grenades lacrymogènes). Lors du premier affrontement filmé, l'opérateur se tient au centre de la manifestation et filme, du point de vue des opposants, le déploiement policier, les CRS qui chargent et attaquent les manifestants à coup de lacrymogènes. La caméra est sans cesse en mouvement, les plans sont brefs et discontinus, l'opérateur filmant notamment en gros plan une grenade lacrymogène qui tombe à ses pieds. L'effet induit sur le spectateur est celui d'une immersion dans la manifestation.

Le film a une fonction de popularisation de la lutte. Parmi les actions publiques spectaculaires menées par les ouvriers pour médiatiser leurs revendications, une quinzaine de caravanes est tirée à la main sur l'autoroute qui conduit à Saint-Nazaire; l'incongruité de la séquence est saisissante. L'équipe de tournage s’immisce également dans les lieux occupés, usine comme préfecture. Une centaine d'ouvriers de Trignac se rendent à la Direction de l'aménagement du territoire de Nantes pour faire valoir leur point de vue. Les ouvriers et l'équipe de tournage occupent pacifiquement les locaux, retenant quatre policiers et deux commissaires dans les bureaux; 150 ouvriers sont bloqués au rez-de-chaussée et tout autour, des cars de CRS encerclent le bâtiment
32 Dans le cinéma ethnographique, la notion de «caméra participante» est mobilisée, notamment par Luc de Heusch (Cinéma et sciences sociales. Panorama du film ethnographique et sociologique, Paris, UNESCO, 1962), pour décrire une dynamique d'interaction qui rompt avec la notion de captation filmique ou d'enregistrement objectif. Jean Rouch popularisera cette notion ( LLa caméra et les hommes" [1973], dans Claudine de France, éd., Pour une anthropologie visuelle, Paris/La Haye/New York, Mouton, 1979), que Heusch emprunte à un anthropologue (George Granai, «Techniques de l'enquête sociologique») pour analyser les films de Robert Flaherty.
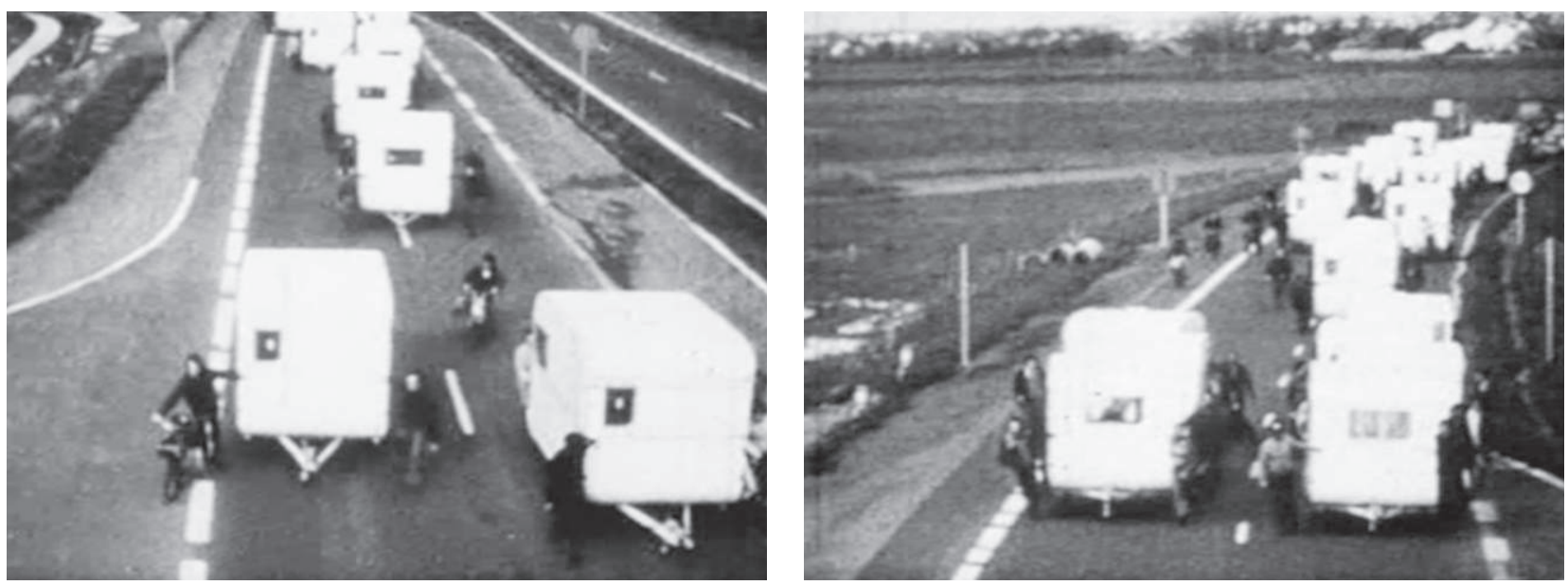
33 René Vautier dénonce en voix over: «Les serviteurs de la loi ont aujourd'hui l'air de ne pas trop tenir compte de la loi elle-même. Il y a en face de nous une section de CRS et devant, quelques policiers.»

34 Vautier s'adresse d'un ton sarcastique au représentant de l'ordre: «Monsieur le commissaire, la loi exige que la séance soit publique, que l'accès soit libre; vous vous opposez à la loi; pour un commissaire cela s'appelle une forfaiture, vous le savez?» et les rues attenantes. A cette occasion, René Vautier s'adresse au commissaire en chef, précisant qu'il tourne avec l'UPCB un film sur les problèmes de l'emploi dans la région; il lui demande pourquoi les délégués des ouvriers ne peuvent pas s'entretenir comme convenu avec le responsable de l'aménagement du territoire. Les deux dernières parties du film multiplient les scènes d'affrontement entre les manifestants et les forces de l'ordre.

Ainsi, les ouvriers de la SEMM-SOTRIMEC de Trignac se rendent à une réunion du Conseil général de Loire-Atlantique, où l'on doit aborder la question de l'emploi dans la région; l'accès à la salle est interdite par les CRS, ce qui est contraire à l'esprit de la loi, comme ne manque pas de le souligner René Vautier en voix over ${ }^{33}$. L'opérateur alterne entre des plans sur les policiers et les manifestants, filmant notamment les forces de l'ordre qui photographient les ouvriers. La tension monte d'un cran. L'équipe de tournage se tient au centre, l'opérateur filmant à travers des panoramiques de 360 degrés d'une part les CRS, se rapprochant des casques, captant le regard de certains d'entre eux, d'autres masquant de leur main l'objectif de la caméra, et d'autre part les manifestants qui entonnent l'Internationale. La caméra est intrusive: elle scrute jusque dans les moindres détails les attitudes et les mimiques des CRS, devenant provocante. Parallèlement, Vautier interpelle le commissaire ${ }^{34}$, cherchant la confrontation.

La séquence suivante dans le film est dévolue à la «séquestration» du patron. L'arrivée du patron «liquidateur», accompagné de deux huissiers, est introduite par un ouvrier qui joue du clairon, annonçant la charge. Les ouvriers empêchent le patron de mettre fin à la réunion, en lui posant des questions pendant deux heures - ce qui sera interprété par la justice comme une séquestration. Dans une salle de conférence, le patron, l'air renfrogné et dénégateur, est assis les bras croisés, les deux huissiers se tenant à ses côtés; les ouvriers, se tenant tous debout, exigent, certains sur un ton enjoué, des explications. Des cartons marquent l'intervention de la censure, deux plans du film ayant été coupés: ils désignent et accentuent au lieu d'effacer ce qui devait être masqué, dissimulé à l'attention du public. Deux cartons se succèdent: «Ici se trouvait un plan de 5 secondes de tête de patron dépeigné. Il fut censuré par le tribunal de Saint-Nazaire.» «C'est la première fois qu'un tribunal fait couper une tête de patron.» Les cartons proposent une ver- 


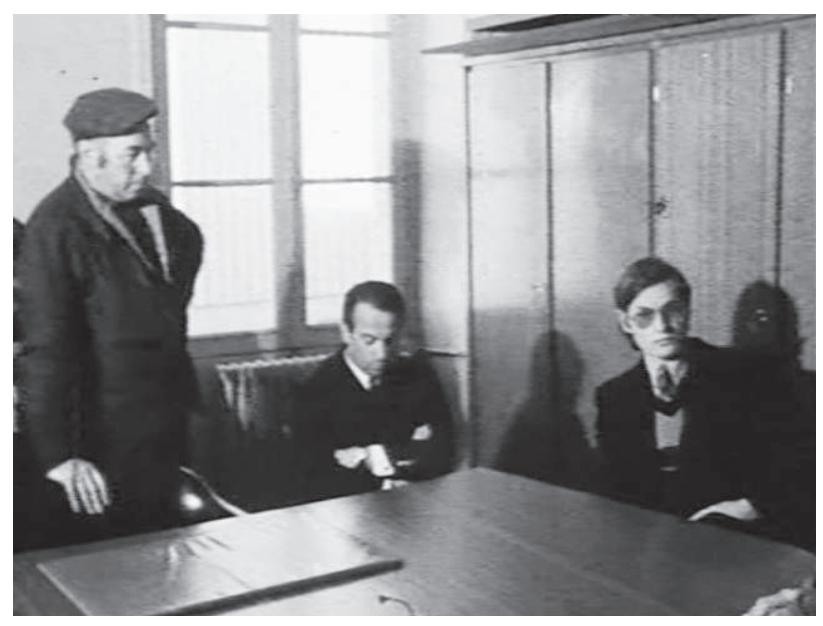

balisation du plan interdit, tournant en dérision la décision de justice, en jouant sur les mots (et en introduisant une référence à la décapitation). Après un contre-champ sur les ouvriers et le délégué de la CGT, un troisième carton intervient: «Ici se trouvait un plan de 9 secondes de patron dépeigné maintenu sur sa table par ses ouvriers. Il fut censuré par le tribunal de Saint-Nazaire.» Les plans qui suivent prennent la mesure des conséquences de cette «séquestration»: à savoir l'inculpation de neuf militants de la CGT (et non de la CFDT), comme le précise René Vautier face aux secrétaires de la CGT et de la CFDT qui dénoncent d'une voix unie cette politique de la division. L’opérateur zoome ensuite dans un article sur le jugement paru dans la Vendée Pays de Loire Bretagne, et cadre, sous le titre: «Pour «séquestrations et violences légères`», les lignes suivantes:

«A la fin de son réquisitoire, il signala que $\mathrm{M}^{\mathrm{e}}$ Chénard avait été, à tort, considéré comme responsable de l'échec, mais que le vrai motif de cette scène était de permettre à un 'gâcheur de pellicule) (ce terme provoque de très vives réactions dans la salle) de faire un film sur cette affaire. Il précisa que seule une infime partie du personnel avait eu une attitude 〈contraire à la dignité humaine`.» 
35 Claire Devarrieux, «Dix-huit mois de la vie des femmes", entretien avec Soazig Chappedelaine et René Vautier, Le Monde, 3 novembre 1977.
A travers cette dimension réflexive ou métadiscursive, le film met en parallèle deux modes de médiatisation opposés: le discours journalistique et un film de popularisation d'une grève. Suivant une rhétorique plus convenue dans le cinéma militant, le film se referme sur le commentaire de Vautier en voix over en relation de contrepoint avec des images télévisées de Giscard d'Estaing:

«Voici l'automne et revoici Giscard tout bronzé. Il parle cette fois de relance; l'argent qu'il n'avait pas pour éviter le chômage de centaines de milliers de travailleurs, il l'a trouvé, c'est le nôtre, et il en donne royalement $80 \%$ aux patrons. 〈Le changement dans la continuité`. Quinze mois de pouvoir giscardien, après quinze ans de pouvoir UDR, et une nouvelle fois sur les petits écrans, dans chaque foyer, on susurre des promesses et les mensonges. En face, nos images...»

Suivent des plans de manifestations...

\section{Quand les femmes ont pris la colère, ou le cinéma d'intervention sociale au prisme des luttes des femmes}

Quand les femmes ont pris la colère (Soazig Chappedelaine, avec René Vautier, I977, $67 \mathrm{~min}$ ) aborde, d'un point de vue féminin, les luttes ouvrières, en dressant le portrait de femmes d'ouvriers. René Vautier, qui a été sollicité à l'UPCB pour filmer la grève à l'usine de Tréfimétaux, à Couëron, ne tarde pas à faire appel à Soazig Chappedelaine, ce film ne pouvant être réalisé que par une femme. René Vautier décrit en ces termes la genèse de Quand les femmes ont pris la colère, à l'occasion d'un entretien:

«Ce sont des ouvriers de Saint-Nazaire qui nous ont signalé qu'il y avait des femmes qui avaient besoin de nous. [...] Il s'agissait d'une grève de huit semaines, rien d'exceptionnel en soi. La seule chose nouvelle, c'était que les femmes avaient pris la lutte en main, sans bien s'en rendre compte, les premiers temps. On a donc écouté, observé, avec patience; on a fait un constat. Le film s'est fait en dix-huit mois, on a suivi le cours des événements. [...] Dans les événements qui s’imprimaient sur la pellicule, il y avait quelque chose qui me dépassait: le problème des femmes.» ${ }^{35}$

La situation politique particulière traversée par les ouvriers et les ouvrières de Tréfimétaux appelle donc une autre analyse que celle d'un 
mouvement social global, les femmes constituant elles-mêmes une minorité au sein des organisations ouvrières (en l'occurrence, la CGT, voire même l'Union des femmes françaises, qui est en quête d'une reconnaissance auprès des organisations syndicales). Soazig Chappedelaine ne manque pas de préciser que le film, s’il avait été dirigé par Vautier, ne se serait pas centré sur le témoignage des douze femmes inculpées à Tréfimétaux suite à leur action de solidarité avec les grévistes del'usine:

«Si René Vautier avait poursuivi lui-même le film, il aurait montré la lutte, avec ses différentes composantes. J'ai préféré m’en tenir à l'action des femmes, et à ce qu'elles avaient à dire sur leur lutte.» ${ }^{36}$

Le film est donc centré sur des entretiens, en interrogeant l'articulation entre l'intime et le collectif, la vie privée et le militantisme social. Vautier prend en charge la conduite des entretiens ${ }^{37}$, tandis que Bruno Muel, Théo Robichet et Pierre Clément signent l'image. Le film, en multipliant les entretiens, donne à voir et à entendre une série de prises de paroles de femmes sur leur condition d'ouvrière, leur vie de couple, leurs activités familiales et leurs tâches quotidiennes. Il ne s'agit pas là seulement d'un témoignage exceptionnel sur la liaison entre lutte sociale et conditions des femmes - ce qui a pu conduire Claire Couzot à affirmer: «nous avons notre Harlan County français » ${ }^{38}$-, mais encore d'un appel à l'action et à la mobilisation, comme le souligne bien Vautier:

«Et, à partir d'un certain moment, en montrant un prémontage du film en cours, c'est devenu du cinéma d'agitation. Pas du ‘ciné-prop`, ce qui aurait été négatif, mais bien du «cinagit `... Le procès qui se préparait nous a permis de mobiliser les gens sur la lutte des femmes.» 39

En donnant la parole aux protagonistes visées par le procès intenté par le patronat, Quand les femmes ont pris la colère permet de faire valoir leurs doléances, malgré le conflit d'intérêts latent entre structures syndicales et revendications féministes ${ }^{40}$.

\section{Ibid.}

37 A ce sujet, Soazig Chappedelaine déclare: «J'ai voulu que René Vautier continue à poser les questions parce que je suis arrivée au milieu du tournage et aussi parce qu'il faut une certaine ha-
38 Claire Clouzot, "Festival de Paris: Quand les femmes ont pris la colère. Le combat qui les rend plus belles», Le Matin, 5 novembre i977. Rappelons que Harlan County, USA (Barbara Kopple, I976) retrace de l'intérieur les treize mois de grève des mineurs de la Duke Power Company, au Kentucky, en I972-I973; le film se centre sur les témoignages des mineurs et l'entrée des femmes dans la lutte, tout en filmant les piquets de grève et les manifestations.

39 Claire Devarrieux, «Dix-huit mois de la vie des femmes", entretien avec Soazig Chappedelaine et René Vautier, dossier de presse.

40 Sur ce point, voir Dominique Loiseau, «Quand les femmes ont pris la colère», dans Danielle Tartakowski et Françoise Têtard (éd.), Syndicats et associations. Concurrence ou complémentarité?, Rennes, Presses universitaires de Rennes, 2006, pp. 263-272. Dominique Loiseau cite notamment la conférence de presse CGT-Tréfiméteaux du I4 avril 1976: «La lutte des femmes est juste, car il est juste de vouloir vivre mieux. Nous pensons que l'entrée en lutte des femmes aux côtés de leur mari est un pas important dans le mouvement ouvrier. C'est cela la véritable libération des femmes.» Rappelons également que Carole Roussopoulos a consacré à la même période une large part de son travail vidéographique à la position minoritaire des femmes dans l'espace public prolétarien, notamment à travers les collectif Vidéo Out et Les Insoumuses (voir Hélène Fleckinger, éd., Carole Roussopoulos: caméra militante. Luttes de libération des années 1970, Genève, MetisPresses, coll. PlanSécant, 20Io). 


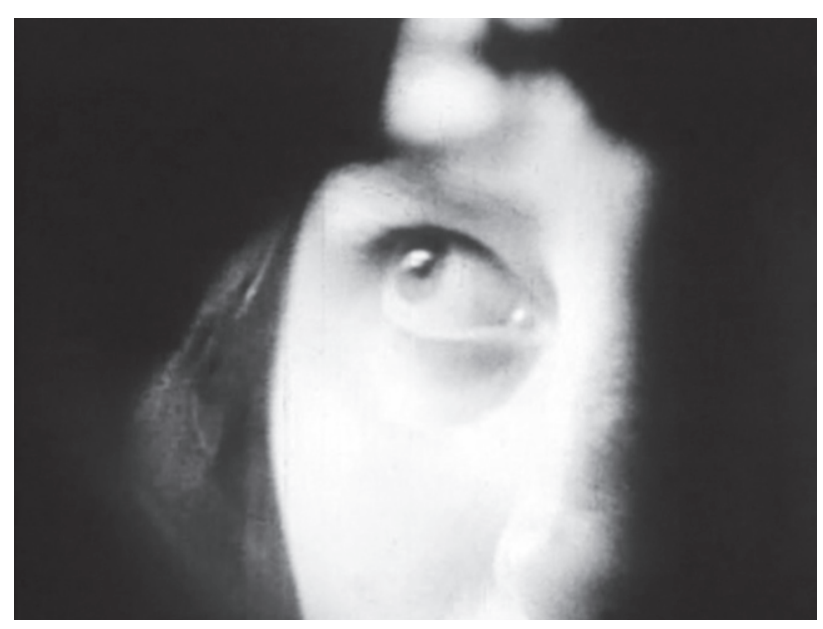

Les premières séquences du film, filmées par Bruno Muel, posent le contexte dans lequel intervient la grève, suivie du mouvement de solidarisation des femmes. A travers deux plans-séquences extrêmement mobiles, les gestes des ouvriers à la chaîne sont filmés, la pénibilité du travail étant soulignée par une musique aux consonances industrielles qui amplifie le vacarme assourdissant des machines; suite à une nouvelle coupe, une ouvrière est filmée derrière sa machine, à travers un cadrage resserré; le plan suivant se concentre sur ses mains en action; autre coupe, son visage est cadré en très gros plan. A travers un nouvel angle de prise de vue, le visage d'une autre ouvrière, dont le regard est rivé sur ses gestes, est cadré en très gros plan, à travers la découpe d'une machine qui produit un effet de surcadrage, comme si la scène était vue à travers un trou de serrure. Les plans alternent alors entre son visage en gros plan et ses mains. Intervient, après une coupe sèche, un plan large sur une manifestation d'ouvriers de Tréfiméteaux, à Couëron. Cette entrée en matière, in medias res, reposant sur des gestes itératifs, signifie très exactement l'aliénation et la dureté du travail à la chaîne, à travers des plans descriptifs dépourvus de tout commentaire: le corps est mécanisé, les gestes sont réifiés, ce qui ne peut qu'induire de lourdes conséquences sur la vie en dehors de l'usine. Le saut brusque de la chaîne 


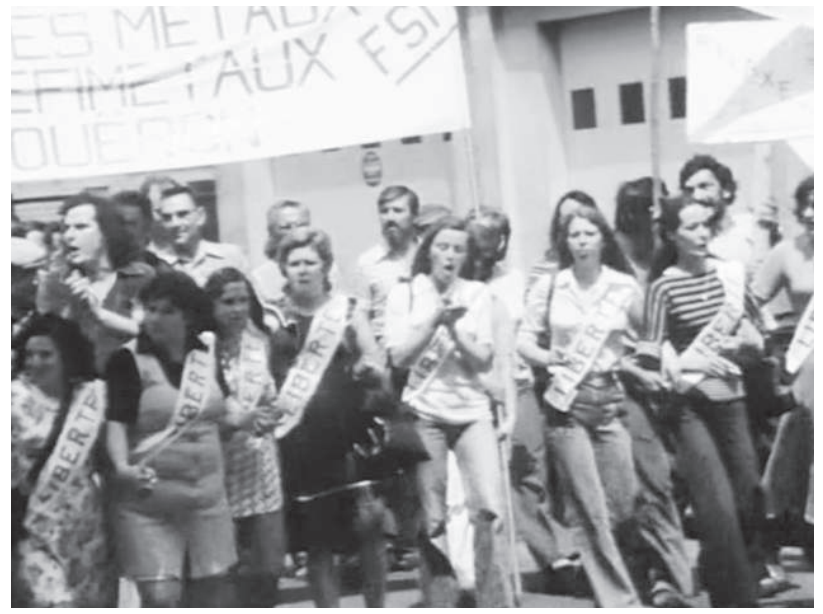

dans l'usine aux plans de la manifestation répond à la logique du champcontrechamp, illustrant le sursaut de la rébellion et l'action des organisations syndicales. Suit alors, ce qui peut surprendre dans la dynamique unanimiste, généralisante, du tournage de ces plans de manifestation, un recentrement, un mouvement de personnalisation, sur trois femmes, arborant une banderole avec le mot «liberté», qui prennent la parole: le film change d'inflexion, rompt pour ainsi dire avec l'exaltation de la mobilisation ouvrière collective. Ces trois femmes, qui font partie des douze inculpées pour avoir «occupé» le bureau du directeur de l'usine qui refusait de les recevoir ${ }^{41}$ - le titre du film fait-il allusion à Douze hommes en colère (Sidney Lumet, 1957)? -, affirment qu'elles ont remporté une première partie. Autre cadrage, elles poursuivent leur propos, tout en évoquant leur camarade et co-inculpée Jocelyne, qui vient d'accoucher; Vautier intervient alors, pour leur demander ce qu'elles pensent du vacarme que font les hommes derrière elles, les empêchant de parler (ceux-ci entonnant l'Internationale avec un porte-voix); elles répondent que ce sont là des mâles, très ambitieux, précisant que le gouvernement fait tout son possible pour que la femme ne soit pas l'égale de l'homme. Si ce plan a été placé en début de film, c'est probablement pour marquer la divergence entre tradition syndicaliste et lutte des femmes; si la
41 La direction de l'usine envoie au domicile de chaque salarié une lettre de mise en demeure, pour faire pression sur les grévistes. Les femmes, dont certaines sont salariées par l'usine, se solidarisent avec les ouvriers, et demandent à être entendues par le patron de l'usine pour lui faire part de leurs difficultés monétaires. Une quarantaine de femmes se déplacent, mais le directeur refuse de les voir. Une vingtaine d'ouvriers et douze femmes entrent dans le bureau du directeur, et le retiennent pendant deux heures pour exposer leur point de vue, en présence de délégués syndicaux. Ces douze femmes seront poursuivies pour séquestration du directeur. 

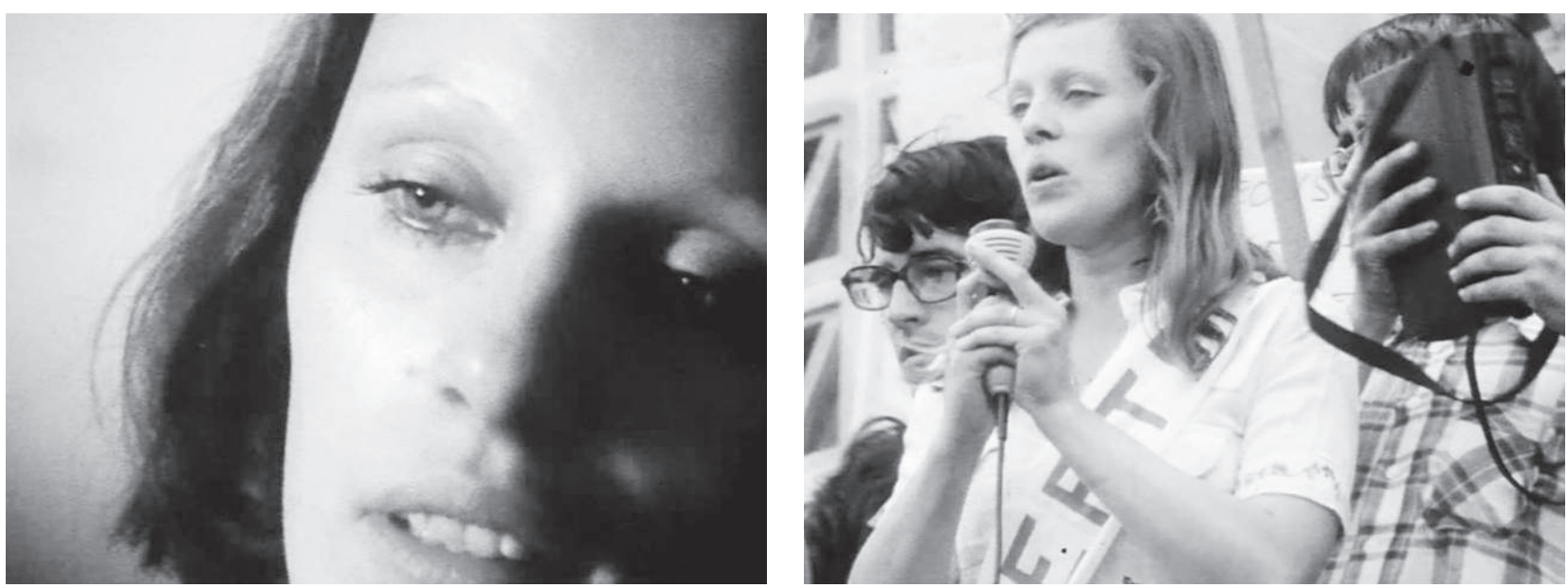

42 Marilène est militante communiste et syndicaliste. Soazig Chappedelaine ne manque pas d'interroger le statut de protagoniste principal accordé à Marilène: «On butte également sur cette question sur la beauté de Marilène et le vieillissement précoce dû aux conditions de travail en usine. C'est aussi sur elle que le caméraman reste le plus souvent. Il y a le côté esthétique, sans doute, mais en fin de compte il n'a pas eu tort, puisque c'est justement elle qui a parlé plus librement.» (P.A.P., «Féminisme et luttes sociales: Quand les femmes ont pris la colère, un film de Soazig Chappedelaine», op. cit.

43 Marilène fait bien évidemment référence ici à l'année internationale de la femme, célébrée en grande pompe par la secrétaire d'Etat à la condition féminine. Pour une déconstruction/détournement de cette «mascarade», voir la bande des Insoumuses Maso et Miso vont en bateau (Carole Roussopoulos, Delphine Seyrig, Ioana Wieder, Nadja Ringart, I975, $55 \mathrm{~min})$. question de Vautier peut en un premier temps être reçue sur le ton de la plaisanterie, elle marque discrètement un clivage plus profond. Surgit alors un raccord sur le «propos»: Marilène, qui répondait à Vautier, est filmée chez elle, en très gros plan, en situation d'entretien.

Quand les femmes ont pris la colère est centré sur une série de portraits féminins, avec Marilène comme principale protagoniste, dont le discours est très construit ${ }^{42}$. Marilène oriente le film du côté du féminisme, en tenant un discours ancré dans sa propre expérience. On peut résumer ainsi ses propos: l'ouvrier OS est oppressé toute la journée à l'usine, subissant les bruits, les cadences et un climat social délétère; sa frustration est palpable - le discours de Marilène se poursuit sur fond d'images de travail à la chaîne. Et quand il rentre à son domicile, retrouve sa femme, qui connaît beaucoup de problèmes (dont ne parle pas Françoise Giroud ${ }^{43}$ ), il voit un mur face à lui, et la frappe; sa rage explose; il y a beaucoup de femmes battues en milieu ouvrier (suit un passage au noir, avant que le plan ne reprenne suivant un cadrage identique) - ce qui n'est pas le cas d'une femme d'ingénieur ou de médecin. Comme le dénonce Marilène, personne n'aborde l'intimité des femmes d'ouvriers - Chabrol s'étend sur les problèmes du couple bourgeois, mais n'envisage jamais le contexte ouvrier -, car cela reviendrait à remettre en cause la 
société (nouveau passage au noir). L'entretien se poursuit, sans que nous n'entendions jamais les questions posées ${ }^{44}$. Le dispositif de captation filmique n'est pas celui du confessionnal, mais celui du recueil attentif d'une parole vindicative qui est adressée à l'autre (ce n'est pas tant l'opérateur ou le preneur de son mais bien d'autres ouvriers et ouvrières qui sont visés comme principaux interlocuteurs de ce cette déposition; le
44 Vautier intervient de façon assez volontariste dans la rue, pendant les manifestations, tout comme à l'occasion d'entretiens au domicile des inculpées ou en extérieur, seules, en groupe ou en famille. Il est dès lors vraisemblable que ses questions ont été coupées au montage dans cette séquence inaugurale.
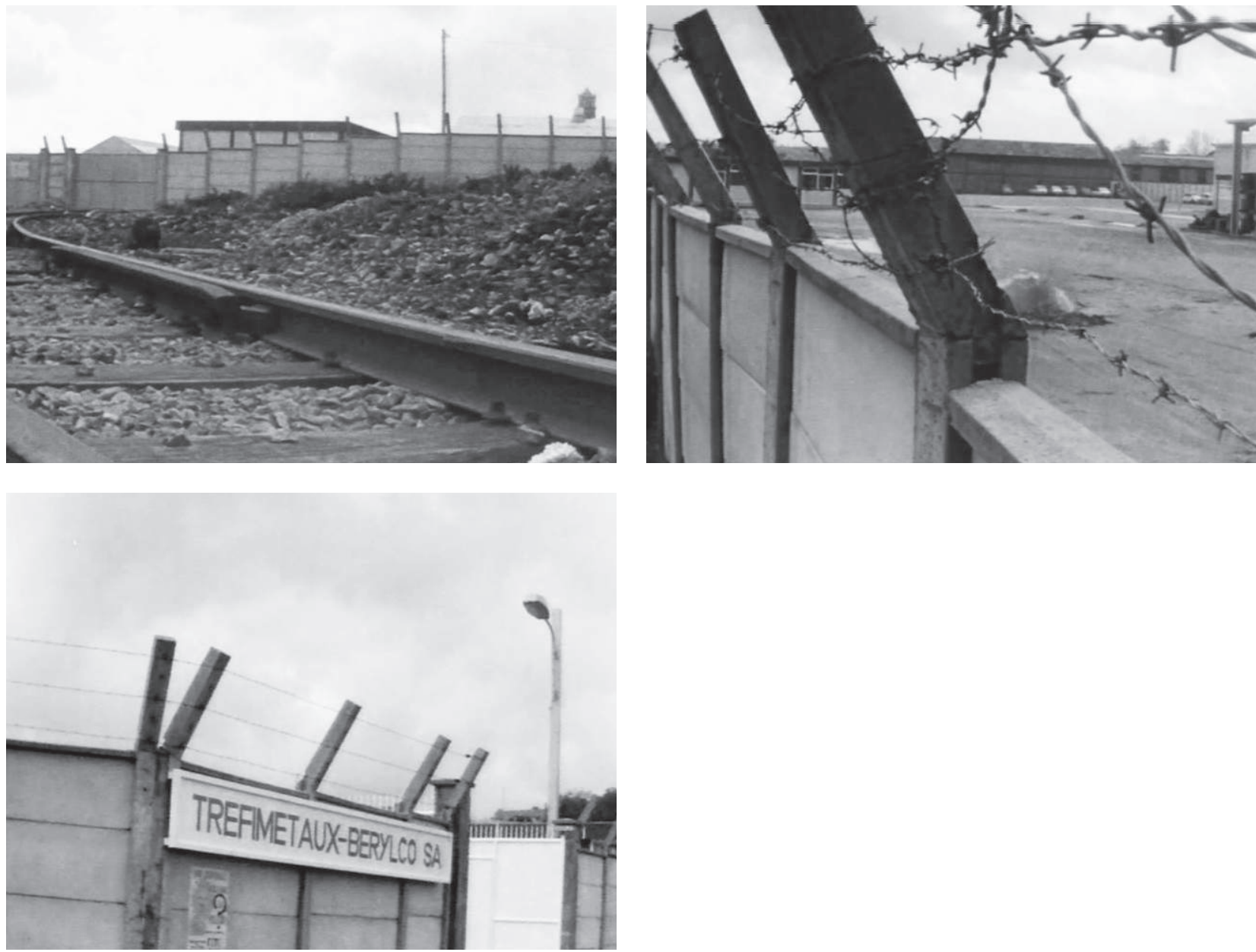
45 Dans le reste du film, lorsque des plans «intercalaires » interviennent, ils ont une fonction d'illustration des propos tenus. La séquence analysée repose sur une logique qui est nettement plus argumentative, le montage contribuant à construire le discours véhiculé par le film en évoquant des comparants historiques (camps de concentration, occupation musclée de l'usine évoquant Mai 68) qui ne sont pas mobilisés par Marilène. discours est de part en part traversé par une dynamique dialogique). Et du reste, le film ne tarde pas à élargir son propos, en s'émancipant de l'ancrage corporel de la voix: suivant une logique proche tantôt de l'illustration, tantôt du contrepoint, les plans sont cette fois tournés majoritairement en extérieur, en s'approchant du lieu du conflit. Lorsque Marilène évoque la situation des ouvriers en vacances, à la mer, c'est la réalité de l'usine qui est montrée: un mur surmonté de barbelés, avec l'inscription Tréfimétaux-Berylco SA; des rails qui conduisent à l'usine et évoquent un camp de concentration. Retour sur Marilène qui poursuit son explication: en vacances, l'homme participe aux travaux ménagers, le couple connaît une sexualité plus épanouie, et les enfants sont heureux. On revient ensuite sur la cour de l'usine, avec les barbelés à l'avant-plan, et un feu qui brûle sur le parking (signe de l'occupation du lieu de travail). Suit alors un travelling latéral, depuis une voiture, qui longe le mur de l'usine. Le montage a une fonction authentiquement discursive, il prolonge et infléchit les propos de Marilène, explicitant l'une de ses revendications implicites: à savoir l'appropriation de l'outil de travail. La séquence se clôt sur ce long travelling, où alternent deux voix over: pastichant le ton suave d'une annonce publicitaire, une première voix vante la stabilité des emplois dans l'entreprise Péchiney, dont dépend Tréfimétaux; une seconde voix, qui s'ancrera rétrospectivement dans la séquence qui suit, fait le point sur la situation des femmes inculpées par l'entreprise Tréchimétaux. En effet le plan suivant cadre le rassemblement des ouvriers et des ouvrières solidaires avec les «douze» de Tréchimétaux; après plusieurs coupes, on découvre une femme lisant une lettre qui résume les événements. Cette alternance ou cette déliaison entre la voix et l'image est beaucoup moins présente dans la suite du film ${ }^{45}$; elle signale ici la prise de position de l'UPCB qui ne se limite pas au «constat», mais qui articule le social au familial, et cette lutte à un contexte plus large d'oppression de classe. Quand les femmes ont pris la colère parvient étonnamment à proposer une synthèse entre féminisme et mouvement syndical, alors que tout les sépare dans les faits à cette période; ceci est d'autant plus remarquable, quand on connaît l'attachement de Vautier au PCF (il est par ailleurs secrétaire du Syndicat des techniciens du film CGT).

Par instants, le film renoue avec l'implication active de l'équipe de tournage dans la lutte, procédé caractéristique du cinéma de Vautier. C'est le cas lorsque les ouvriers se regroupent devant le tribunal et sont 
empêchés d'assister au procès des «douze». Des policiers ouvrent la grille à un représentant de la justice; René Vautier en profite pour lui emboîter le pas, malgré l'hésitation des policiers. Le plan suivant est tourné de l'autre côté de la grille: les forces de l'ordre laissent entrer quelques personnes, avant de refermer les grilles à clef. En contre-plongée, la caméra cadre les dix inculpées ${ }^{46}$ (avec deux représentants de la CGT), se tenant les bras croisés, au sommet des escaliers menant au tribunal, et portant une banderole arborant le mot «liberté». Retour sur la porte grillagée qui conduit au tribunal: deux syndicalistes insistent auprès d'un fonctionnaire de la justice pour franchir les grilles qui les séparent du tribunal, la foule étant massée derrière eux; Vautier, de l'autre côté de la grille, témoigne du fait que la salle du tribunal n'est pas pleine. Une fois les syndicalistes entrés, les ouvriers forcent la porte, tandis que des policiers cherchent en vain à les repousser. Ici, l'équipe de tournage participe au grippage du fonctionnement de la machine judiciaire et policière, par sa présence, sa fonction et son action.

Mais le film ne propose pas pour autant un portrait enthousiaste, sans nuances, de la lutte, prenant également la mesure des répercussions du conflit (malgré le non-lieu prononcé quelque dix-huit mois après les inculpations). Certaines inculpées se sont séparées de leur mari, ont perdu leur travail. Lors du dernier entretien avec Marilène, monté en alternance avec deux autres inculpées - l'une avec son mari et ses enfants, l'autre séparée et restée longtemps sans travail -, celle-ci revient sur sa situation. En instance de divorce, Marilène dénonce la situation des femmes ouvrières qui vont accoucher, qui n'est pas comparable à celle d'une bourgeoise; comme elle le précise, aucune précaution n'est prise avec la femme ouvrière, ce qui génère des troubles psychologiques et entrave sa sexualité; ainsi, lors de son accouchement, le médecin a oublié de retirer une partie du placenta, ce qui a nécessité un curetage, et a finalement causé son infertilité et une santé déficiente, précipitant la rupture avec son mari. Le film se termine alors, comme il s'était ouvert, sur des plans d'ouvrières à la chaîne.

\section{Marée noire, colère rouge ; "les pollueurs sont les payeurs "}

René Vautier s'engage également avec l'UPCB dans le militantisme écologique. Lorsque le pétrolier Amoco-Cadiz coule au large de Porstall, dans le Finistère, le ı6 mars 1978, et que 230 tonnes de mazout se
46 Une femme inculpée est sur le point d'accoucher, tandis qu'une autre vient d'accoucher. Dans la chronologie des événements, cette scène suit immédiatement la première séquence que nous avons décrite. 
47 Le film n’a pas été diffusé sur les chaînes télévisées françaises, les responsables de celles-ci exigeant des coupes (en particulier, des manifestations qui dénoncent la campagne de désinformation de la télévision). déversent dans la mer, la population bretonne fait appel à Vautier et à l'UPCB pour témoigner de la réalité du naufrage, minimisée par la presse et les actualités télévisées. Commande sociale, Marée noire, colère rouge (1978, $65 \mathrm{~min}$ ) incite à la mobilisation les riverains, les pêcheurs, les agriculteurs et plus largement les citoyens du Finistère, dénonçant la corruption politique des médias qui dissimulent l'étendue de la pollution et les mesures dérisoires mises en ouvre par le gouvernement - ce qui conduit les manifestants à scander dans la rue: «radio, télé, informations bidons». Marée noire, colère rouge est présenté quelques semaines après le naufrage, en Bretagne ${ }^{47}$. Rapidement, le film est mis au service d'une campagne de revendication internationale: il est projeté auprès des populations concernées par la marée noire, notamment en Espagne et en Alaska, auprès des Inuits du Nord-Canada. Le film, dans sa fonction de popularisation, concourt au mouvement de mobilisation populaire qui a pour but d'instituer le principe «les pollueurs sont les payeurs», qui sera reconnu des années plus tard par les tribunaux.

Marée noire, colère rouge s'ouvre et se clôt sur des vues aériennes, des mouettes volant au-dessus de la mer, évoquant une nature qui n'est pas encore souillée par les grandes compagnies pétrolières. S’ensuit une série d'entretiens, avec le secrétaire du Comité local des pêches mari-

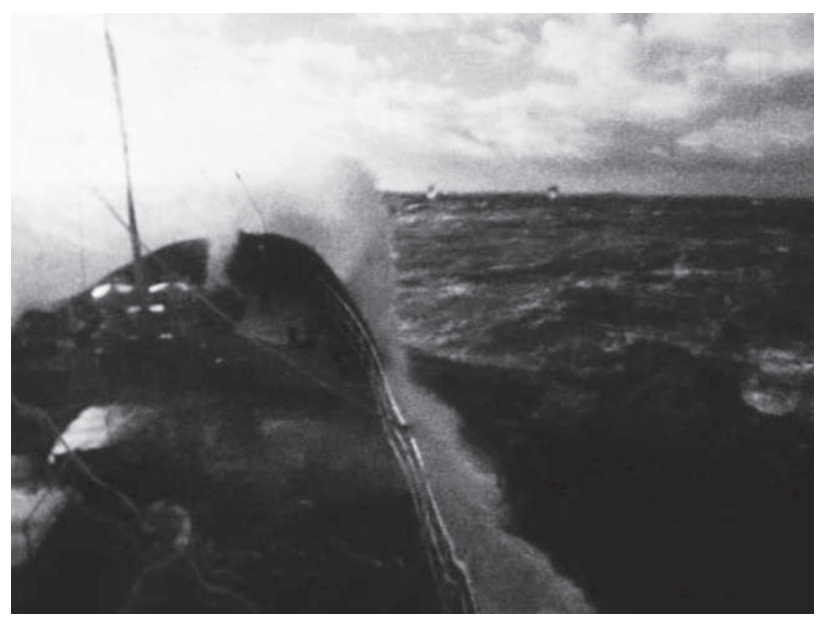



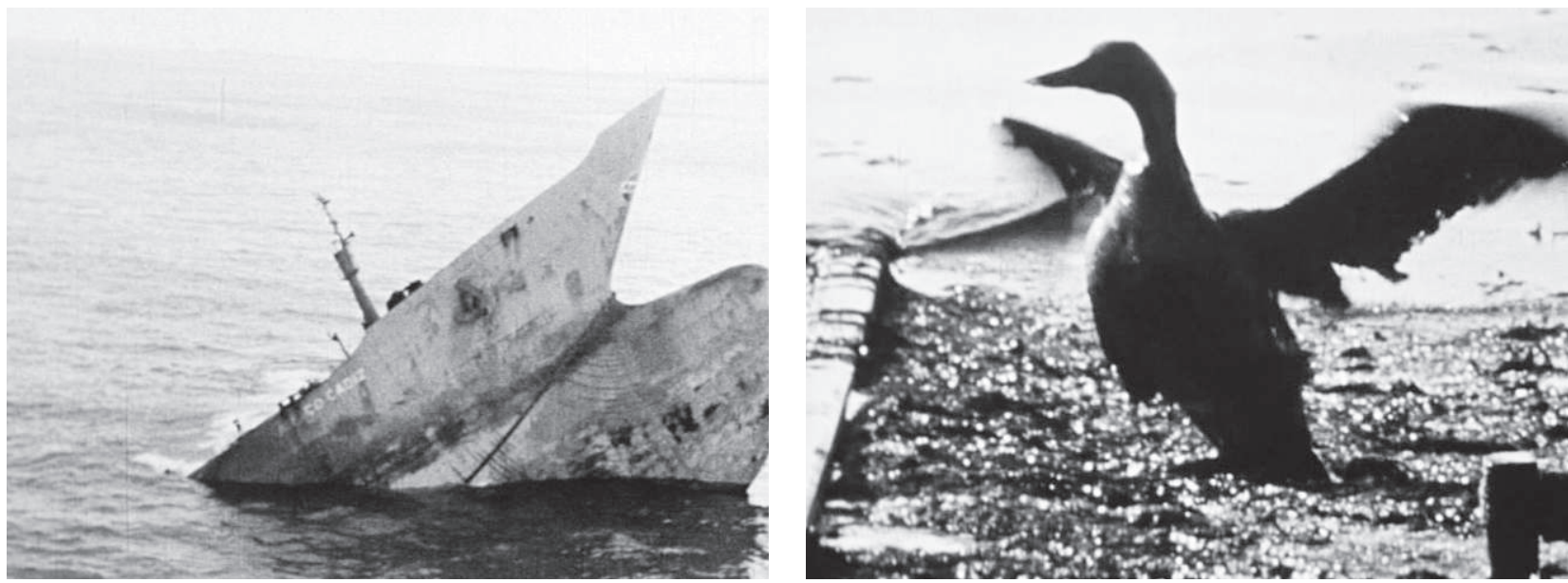

times, avec un scientifique, ou encore avec un maître de conférence en écologie à l'Université de Bretagne occidentale (UBO). Le film expose les mécanismes scandaleusement spéculatifs du sauvetage en mer. La caméra filme, depuis le poste de pilotage, le pont d'un bateau balayé par les vagues; le plan est semi-subjectif, pouvant renvoyer à la situation de l'Amoco-Cadiz pris dans la tempête. En voix over, Vautier explique le principe des «charognards de la mer»: conformément au libéralisme de la loi de l'offre et de la demande, la somme exigée pour le remorquage fait l'objet de négociations. Les plans suivants, filmés à travers un hublot, cadrent la mer, le soleil et les mouettes. Vautier rapporte les échanges qui se nouent entre Chicago et Hambourg au sujet de l'Amoco-Cadiz; l'accord est finalement conclu, mais le vent est trop fort, le pétrolier s'écrase contre des rochers et commence à «saigner son pétrole». Suivent des vues aériennes qui montrent l'étendue de la pollution ${ }^{48}$, tandis que Vautier prend à parti les mass media qui minimisent l'événement, trahissent leur mission, en se prêtant à une déformation et à une manipulation de l'information. Le cinéma a littéralement une fonction de révélateur dans Marée noire, colère rouge: Pierre Clément et René Vautier attestent, avec l'objectivité impa48 Vautier, avec le soutien actif de la population locale, embarque dans l'hélicoptère affrété pour les journalistes, malgré le refus des autorités à accueillir la caméra de l’UPCB. rable de la caméra, la présence concrète du mazout, l'étendue de la marée noire, les images pathétiques d'oiseaux englués, etc.; Vautier précise, en 
49 Voir Manthia Diawara, African Cinema: Politics and Culture, Bloomington, Indiana University Press, 1992, p. 93 . voix over, que les accidents et les suicides se multiplient dans le Finistère - ainsi, un mécanicien se suicide dans l'eau polluée du port avec sa voiture; «la télévision», comme le précise Vautier, «montre dix fois l'oiseau, jamais l'homme». Le film est structuré suivant l'opposition, sur la bande son, entre les informations télévisées reproduites avec leur jingle et la voix de Vautier qui constate et dénonce. Aux dégâts causés par le pétrolier répondent les images de manifestations, avec des slogans entonnés tels que «Marée noire, gâchis capitaliste, grève générale», «Ras le bol du pétrole», «Nous sommes tous des pingouins mazoutés».

La prise en charge de Marée noire, colère rouge à travers le réseau de l'UPCB présente l'incontestable avantage par rapport à une diffusion commerciale de circuler en fonction de l'urgence des luttes contre la pollution par le pétrole; le film de Vautier non seulement rencontre un public qu'il participe à mobiliser, mais appelle également le tournage d'autres images, le recueil d'autres témoignages, la réalisation d'autres films.

\section{Prendre en charge la popularisation des luttes}

L'UPCB constitue, on l'aura compris, une plateforme de production ouverte et plurielle, qui repose sur un vaste réseau de collaborations. La logique est collectiviste: un groupe à géométrie variable travaille conjointement. L'ancrage en Bretagne permet également de recentrer les activités cinématographiques de Vautier, qui se déployaient auparavant et continuent néanmoins à s'exercer sur un plan international.

L'utopie du groupe Medvedkine: donner directement la caméra aux militants, impulsée par Chris Marker - mais n'était-ce pas là également le projet de Rouch et de son atelier Super-8 à l'université de Maputo, voire de Godard (employé par la société Sonimage) et de sa volonté avortée de créer une chaîne de télévision, au Mozambique, en $1978^{49}$ ? -, trouve un point de résolution dans cette structure de production. En effet, ce n'est plus tant les cinéastes qui vont sur les lieux de lutte, proposant de les documenter ou de donner la possibilité aux activistes de le faire euxmêmes, qu'un processus inverse qui opère ici: c'est l'ouvrier, le militant, mais aussi le citoyen qui sollicitent l'UPCB en vue de la réalisation d'un film et de la prise en charge de sa diffusion. Un film militant, rappelonsle, s'apparente à un tract diffusé à une échelle de masse (grâce au caractère reproductible du cinéma, qui n’est pas limité par la présence effective des porte-parole d'une revendication sociale ou d'une lutte politique). Sui- 
vant ce même idéal d'«objectivité» de la forme (ce que critiquent précisément les tenants de la déconstruction et des pratiques oppositionnelles - encore que nous pourrions faire remarquer, sur ce point, que le caractère brut, non apprêté, des documents militants se situent aux antipodes de la fausse transparence des actualités télévisées et des codes institutionnalisés du cinéma dit dominant), c'est la masse qui prend la parole et exprime son point de vue par le biais de l'UPCB. La distinction peut paraître spécieuse, mais elle est selon nous fondamentale - en ce sens que les images orientées (et, précisons-le, impulsées) par les militants sont prises en charge par l'outil de production cinématographique, suivant une écriture filmique «objectiviste», ce qui n'est pas synonyme d'absence de style (Bruno Muel, Pierre Clément, René Vautier, pour ne citer qu’eux, sont de remarquables opérateurs, dont le «style» est immédiatement reconnaissable; ils ne visent en aucun cas une «impersonnalité» de l'acte de filmage, un effacement de l'énonciateur, mais bien plutôt une focalisation multiple, décentrée, démocratique - si l'on peut encore recourir à ce terme quelque peu galvaudé: demos kratia, soit le pouvoir du peuple). 